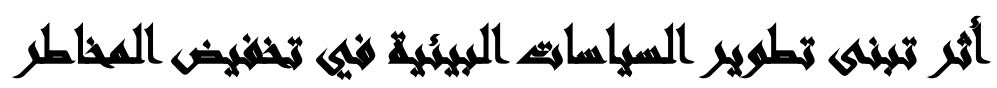

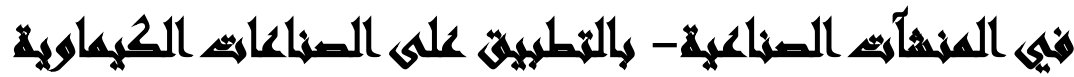

\section{[1 $\leqslant]$}

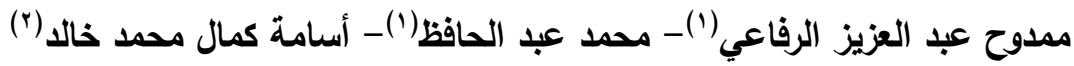

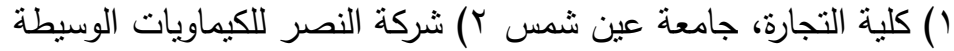

\section{المسنبله}

إن تنبى المؤسسات المصرية وخاصة الصناعية منها لنطوير السياسات البيئية والمتمثلة

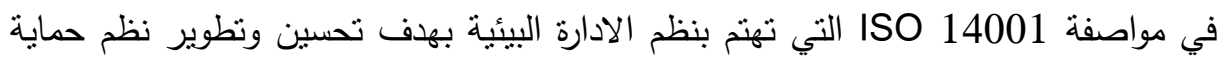

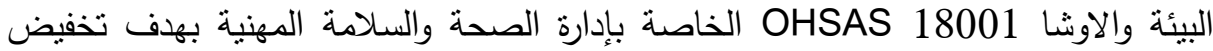
المخاطر التي يتعرض لها العاملين، سوف يحقق الكثير من الأهداف للمؤسسات الصنافة الصناعية

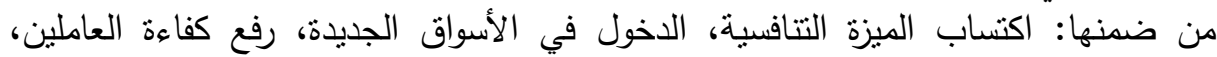

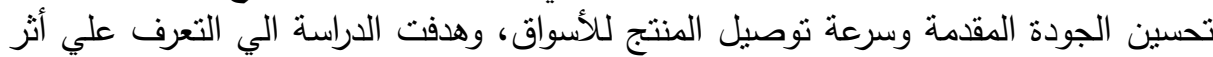

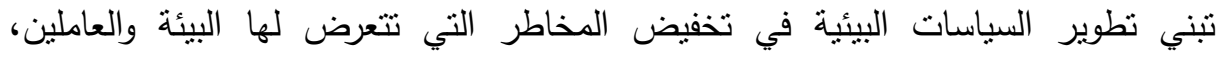

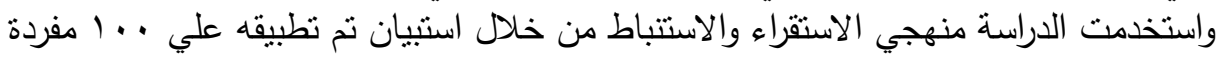

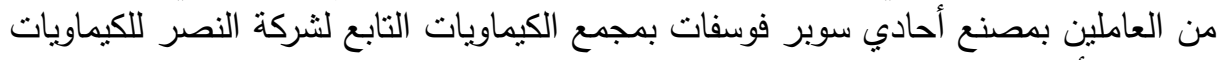

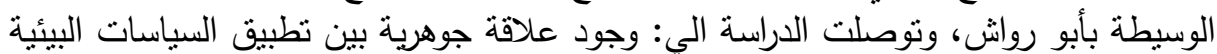

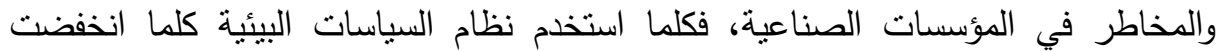

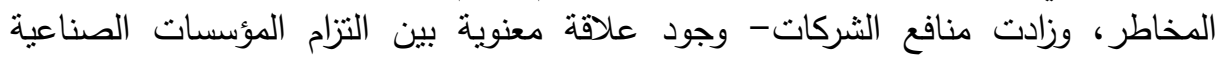

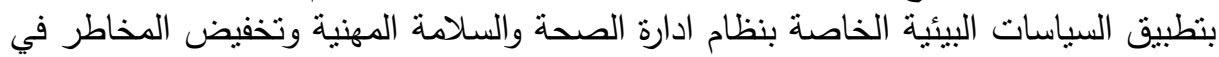

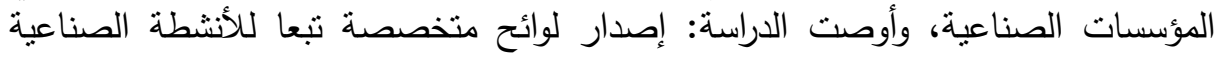
تشتمل علي ضوابط ومعايير مرتبطة بكل نشاط صناعي بما يضمن معايير تخصصية محددة

\section{هוקט}

إن نوفير بيئة عمل آمنة من مخاطر الصناعات المختلفة ورفع كفاءة ووسائل الوقاية سيؤدي بلا شك إلى الحد من الإصابات والأمراض المهنية هي خطر يهدئه عمل عال مصر ويتعرض الآلاف فيهم إلى أمراض مهنية خطيرة ونقص في ساعات العمل والقدرات الإنتاجية فضلاً عما يتفق على علاج الأمراض الناتجة عن العمل والواقع يؤكد أن الأعداد كبيرة 
والاتفاق بملايين الجنيهات ورغم من وجود عثرات الدراسات العلمية التي أجريت على مواقع العمل وأوحت بوضع حد لمخاطر النعرض للملوثات دخل بيئة العلم ورغم النتائج الإيجابية التي ظهرت في العديد من المنشآت إلا أن الخطر لا يزال يهدد الآلاف لمن يفتقدون أبسط القواعد التي تساهم في الحد من مخاطر التلوث المحيطة بهمكا يساهم فقد الوعي البيئي

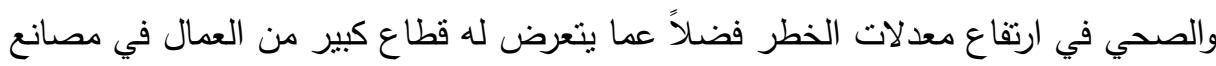

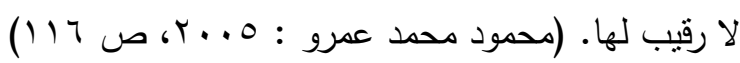
وقد اهتمت كبرى الثركات الصناعية في الدول المتقدمة بمفهوم المسؤولية الاجتماعية

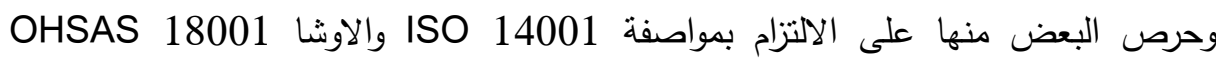
لتحسين توجهاتها الاجتماعية والبيئية، غير أن المؤسسات المصرية بهرات ما تزال بعيدة عن تنبني تطوير هذه المواصفات الدولية الهامة في أنظمتها الإدارية وأنشطتها اليومية.

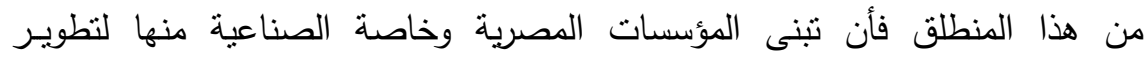
السياسات البيئية والمتمثلة في مواصفة 14001 ISO التي تهتم بنظم الادارة البيئية بهدف وند تحسين وتطوير نظم حماية البيئة والاوشا 18001 OHSAS الخاصة بإدارة الصحة والسلامة المهنية بهدف تخفيض المخاطر التي يتعرض لها العاملين، سوف يحقق الكثير من الأهداف للمؤسسات الصناعية من ضمنها: اكتساب الميزة التنافسية، الاخول في الأسواق لهاق الجديدة، رفع كفاءة العاملين، تحسين الجودة المقدمة وسرعة توصيل المنتج للأسواق.

(Taylor , Jonr : Pollutiants , Vol I Issue 4 , Ap 2004 ) , P. 213) 


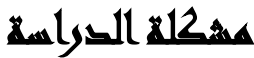

في ظل التغيرات الحديثة التي نواجهه المؤسسات الاقتصادية خاصة القطاع الصناعي لأنه يمثل أحد أهم قطاعات الاقتصاد الوطني ، تعددت المخاطر التي تحد من مزايا وسمات المؤسسات الاقتصادية في اقتصاد السوق المفتوح ، ولكى تسنطيع المؤسسات الصناعية

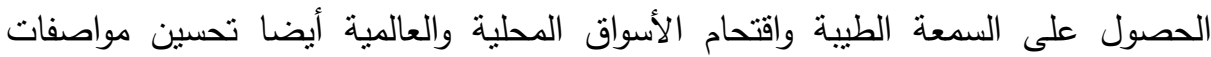
المنتج المحلى يجب عليها أن تقوم بتطوير السياسات البيئية والتي تسعى لحماية البيئة مع الئه توفير احتباجاتها وأيضا حماية السلامة والصحة المهنية. وسعت دراسة منال عمارة إلى نوضيح دور برامج السلامة الصحة المهنية للحفاظ على

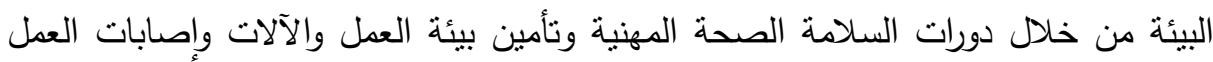
والحفاظ على الناحية النفسية الاجتماعية والصحية للعمال والعمل على تتمية مهارات العمال

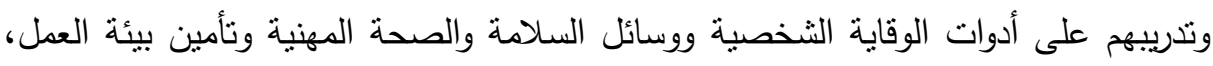
لذلك فإن أهمية الدراسة هي تطوير أداء العاملين وتتمية وعيهم وتعديل سلوكهم وتدريبهم في ولئه مجال السلامة والصحة المهنية وتأمين بيئة العمل وذللك حفاظاً على أرواحهم وحمايتهم وتفاديهم لتلك المخاط، وتوصلت الدراسة الي وجود علاقة دالة احصائياً بين السلوك الإيجابي ولي الئي

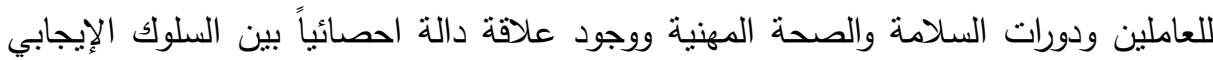
للعاملين الامكانيات المتاحة بالعمل ووجود علاقة دالة احصائياً بين السلوك الإيجابي للعاملين وحوادث وإصابات العمل.( منال محمد سيد أحمد عمارة : 7 أ. ب). وتناولت دراسة حسن عبد الحي إبراهيم كيفية الاستعداد لمواجهة المواقف الطارئة في بيئة العمل، وأن تقييم المخاطر في كافة مناحي الحباة يجعل مواجهة الحوادث المتوقعة أكثر

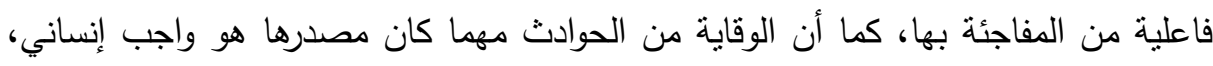
وتقوم إدارة السلامة والصحة المهنية إلى تهيئة بيئة عمل آهنة من أية مخاطر أو حوادثان

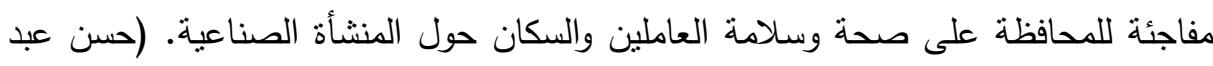

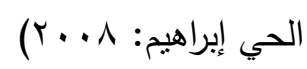


وهافت دراسة طارق المهاي الأرنؤوط إلى دراسة مخاطر بيئة العمل الفيزيائية والكيماوية والهندسية والبيولوجية والنفسية والسلبية وأيضا دراسة النتريعات الوطنية الحاكمة

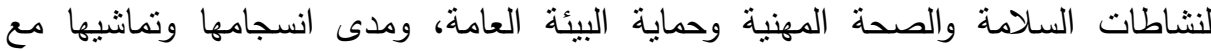
المعايير الدولية في هذا الثأن. ومن أهم النتائج أن هناك غياب مفهوم السلامة والصحة المهنية كعلم يستهدف حماية

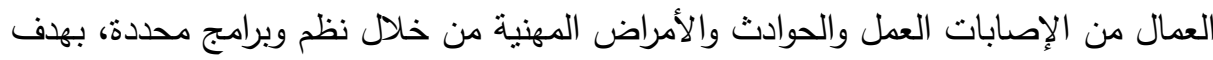

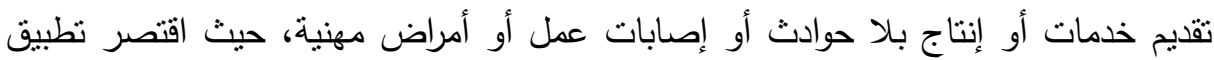

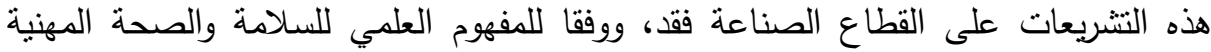
يجب تطبيق هذه النظم والإجراءات على كافة الأنشطة (الصناعية - التجارية - الخدمية -

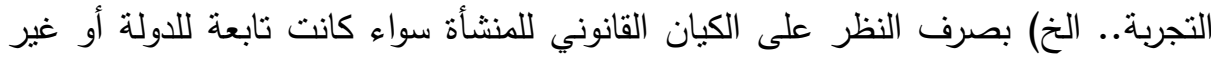

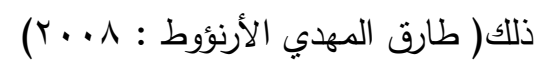

وأيضا عن النتائج للوائح التفيذية المشار إليها لم تتضمن الجداول والمعايير للحدود القصوى للملوثات في بيئة العمل ووسائل تأمين بيئة العمل بشكل بشمل وسائل الحماية الفردية لإية

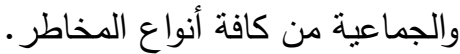

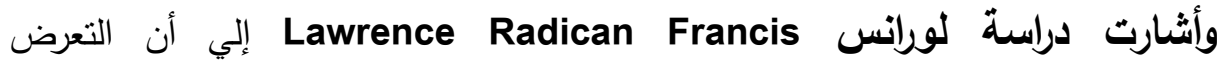
للايدروكربون يزيد من مخاطر الإصابة بأمراض الكلى المزمنة وزيادة نسبة الوفيات (Lawrence Radican Francis: 2008) واهتمت دراسة Graff Susan بطرح سؤال هل يجب على لشركتكم تطبيق نظام

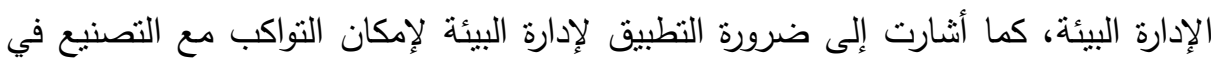

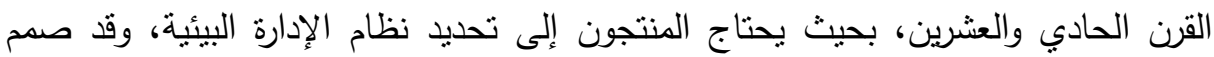

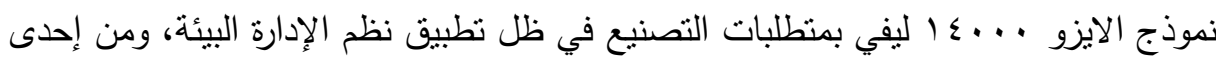

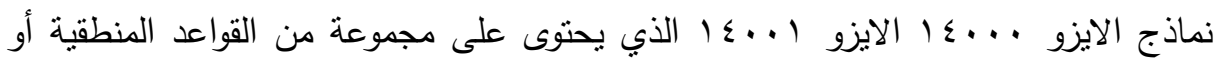
الخطوات لتطبيقه، إلا وهى وضع السياسات البيئية للمنثاة، نم التخطيط، تم التنفيذ، تم 
(Graff.Susan, Iso 14000., المراجعة والتعديل لضمان التحسين المستمر 2011,pp.19.22)

ومن خلال ذلك العرض رأي الباحث أن تبنى تطوير السياسات البيئية من خلال مواصفة الأيزو 14001 ISO الخاصة بنظم الإدارة البيئية التي تهدف لنطوير وتحسين نظام حماية البيئة والأوشا 18001 osha الخاصة بإدارة الصحة والسلامة المهنية ،تخفض من الإدون المخاطر التي تواجه المؤسسات الصناعية وبالتالي تستطيع المؤسسات الصناعية الارتقاء

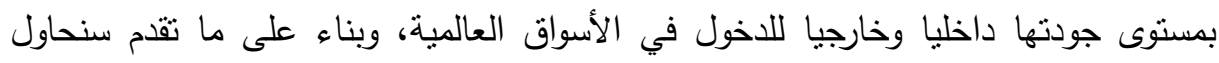

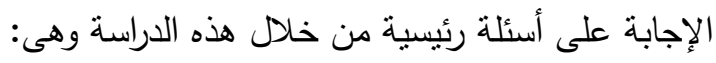

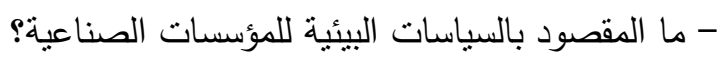

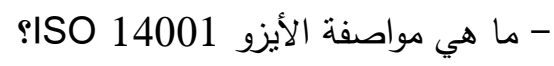

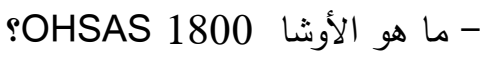

- ما هي المخاطر التي نواجه المؤسسات الصناعية؟ OHSAS إلي أي مدي تسنطيع مواصفة الأيزو 14001 ISO ونظام الأوشا 18001 -

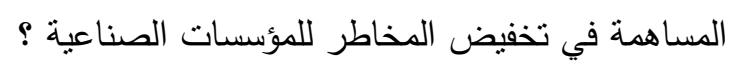

لذلك يعتمد الباحث على العلاقة بين تبنى نطوير السياسات البيئية وتخفيض المخاطر

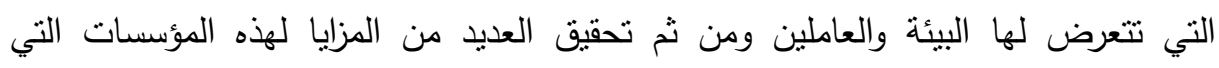
تساعدها في تطوير نشاطها ومواكبة التغيرات العصرية في البيئة الصناعية.

\section{أهمية القواسمة}

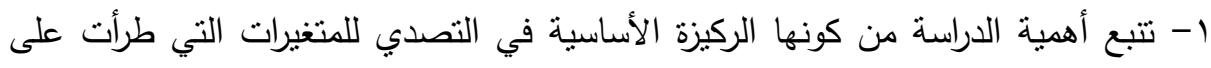
القطاعات الاقتصادية بأكملها ومن أهم هذه القطاعات القطاع الصناعي الذى أصبح حجر الزاوية في التتمية الاقتصادية، مما أدى إلى ضرورة تطوير السياسات البيئية

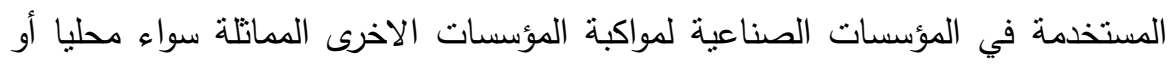

دوليا. 
r- تتضح أيضا أهمية الدراسة من جانبين الجانب الأول هو الجانب العلمي: فهي تتعلق

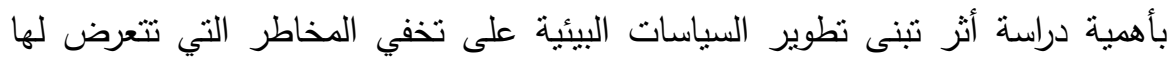

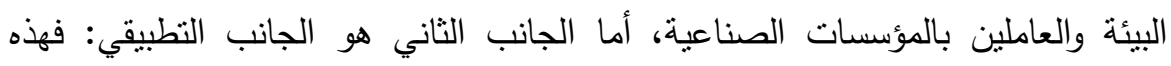

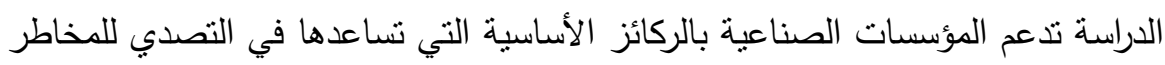

$$
\text { التي تواجهها. }
$$

\section{أهساهيت التراسما}

- التحقق من العلاقة بين نبنى نطوير السياسات البيئية في تخفيض المخاطر في المنشآت

$$
\text { الصناعية }
$$

- التحقق من نأثير هذه العلاقة علي فاعلية و جودة تطبيق الإدارة البيئية - التحقق من نأثير هذه العلاقة علي فاعلية و جودة تطبيق نظام السلامة والصحة المهنية - التحقق من هذه العلاقة علي مسنوي تحقيق التتافس لخدمة البيئة والتتمية المستدامة

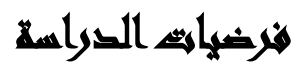

الفرض الرئيس: توجد علاقة معنوية ذات دلالة بين تبنى تطوير السياسات البيئية وتخفيض المخاطر فى المؤسسات الصناعية.

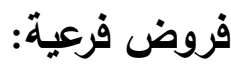

- توجد علاقة معنوية ذات دلالة بين وجود السياسات البيئية وتخفيض المخاطر في المؤسسات الصناعية .

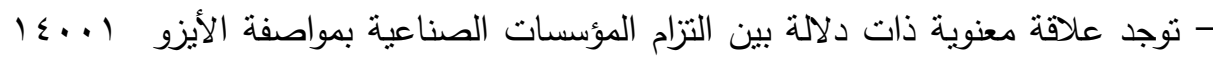
الخاصة بحماية البيئة وتخفيض المخاطر في المؤسسات الصناعية .

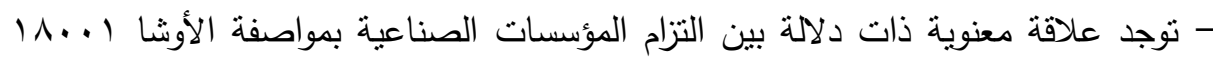

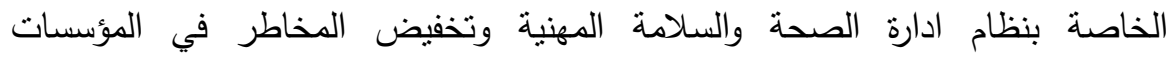
الصناعية. 


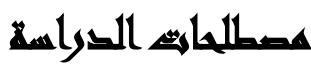

- مفهوم السلامة والصحة المهنية: تعرف السلامة والصحة المهنية بأنها العلم الذي

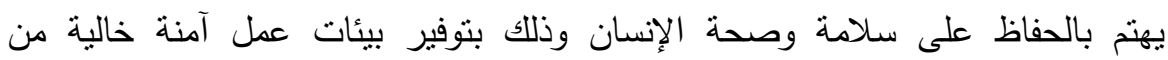

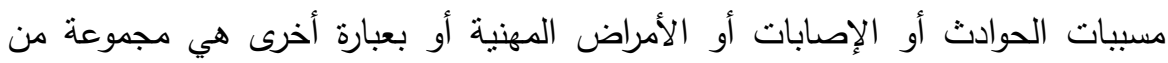

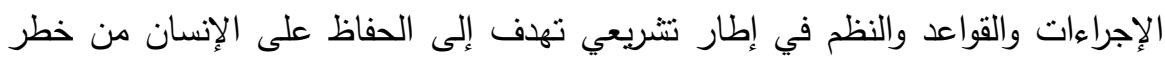

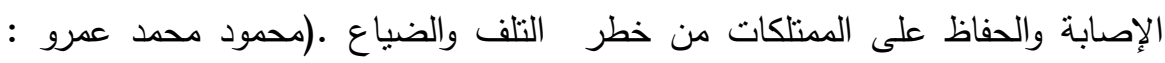

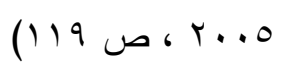

- مفهوم مخاطر العمل: هي مخاطر تنتج عن الأعمال الإنتاجية والثتغيلية بالمنشأة

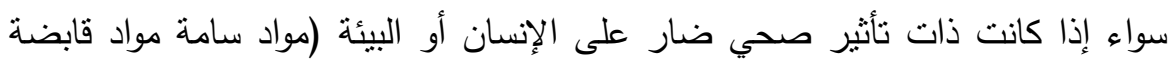

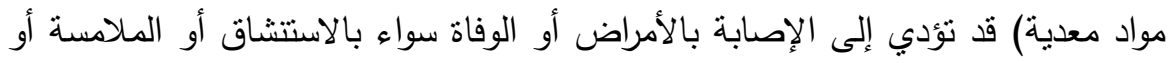

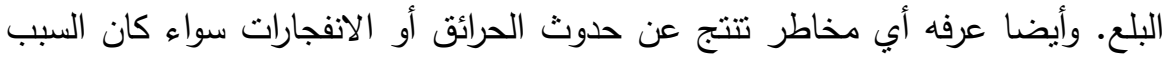

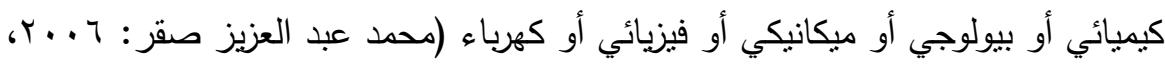

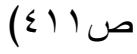

- السياسات البيئية: مجموع الأهداف والإجراءات التي تتناول تتظيم العلاقة التبادلية بين

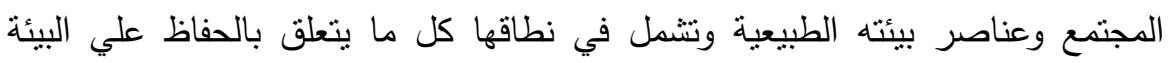

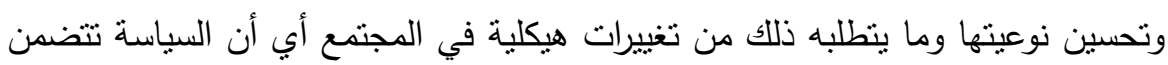

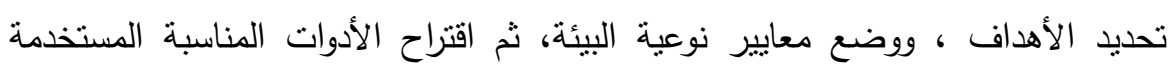

لتحقيق تلك الأهداف. (Franciso Szckely: 2005. p.11) - بيئة المصنع: كما عرفتها إحدى الدراسات بأنها كافة الظروف البيئية التي ينوقف عليها

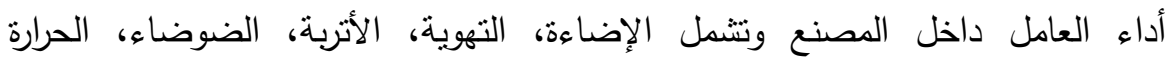

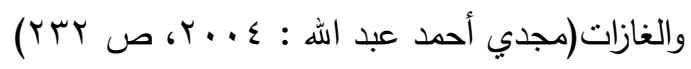




\section{التراسايت الماريه}

ا - دراسة منال عمارة(؟ 1 ( Y): سعت هذه الدراسة إلى توضيح دور برامج السلامة الصحة المهنية للحفاظ على البيئة من خلال دورات السلامة الصحة المهنية وتأمين بيئة العمل والآلات وإصابات العمل والحفاظ على الناحية النفسية الاجتماعية والصحية للعمال والعمل على تتمية مهارات العمال وتدريبهح على أدوات الوقاية الثخصية ووسائل السلامة والهات والصحة المهنية وتأمين بيئة العمل، لذلك فإن أهمية الدراسة هي تطوير أداء العاملين وتتمية وعيهم وتعديل سلوكهم وتدريبهم في مجال السلامة والصحة المهنية وتأمين بيئة

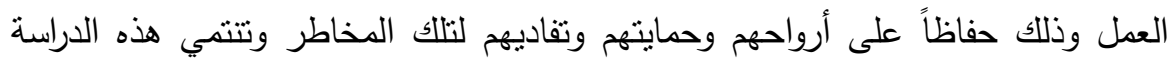
الي نمط الدراسات الوصفية التحليلية باستخدام المنهج الوصفي التحليلي والمسح الاجتماعي بالعينة، ويتمثل مجتمع الدراسة في العاملين في المنشآت الصناعية .

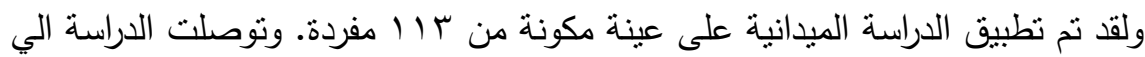
وجود علاقة دالة احصائياً بين السلوك الإيجابي للعاملين ودورات السلامة والصحة المهنية

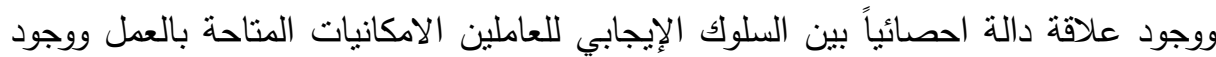

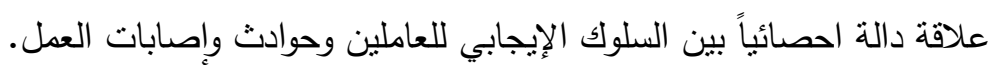

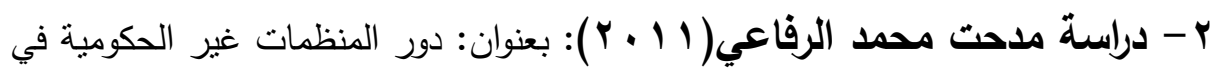

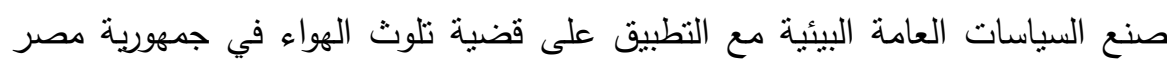

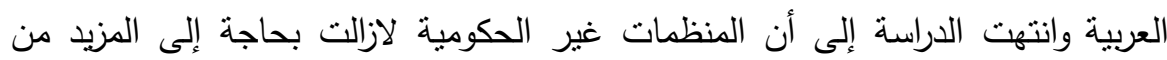
الدعم في مجالات مختلفة يأتي على رأسها الحاجة إلى الاهتمام بالكوادر البشرية العاملة،

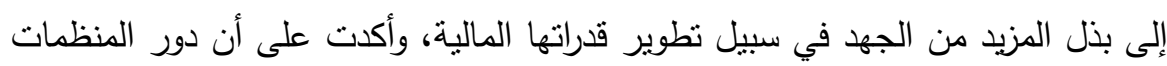
غير الحكومية يبدو أكثر وضوحاً فى مرحلة تتفيذ السياسات حيث تساهم المنظمات البيئية مساهمات متعددة ومنتوعة في تتفيذ البرامج الموضوعة ذاتيا أو الموضوعة بالتنسيق مع

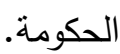




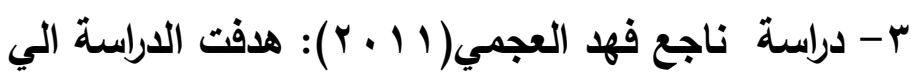

ا-محاولة تأهيل مؤسسات الأعمال بدولة الكويت مع منطلبات المواصفة الدولية الجديد ISO14001

r- المساهمة في تقديم إطار نظري في تتاول الجودة والبيئة وأنظمة إداراتهم للدداخل الحديثة

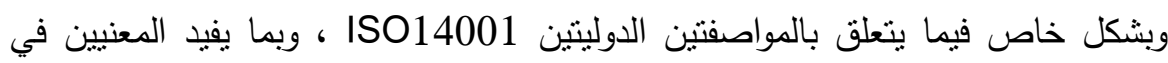
الصناعة والاهنمام بمفهوم الجودة الشاملة. r- تقديم وصف تقييمي للوضع الاقتصادي والبيئي في مؤسسات الأعمال بدولة الكويت مما بمادها يساعد في التعرف على الجوانب البيئية المهمة فيها، مع توصيات ومرئيات لتبني نظام

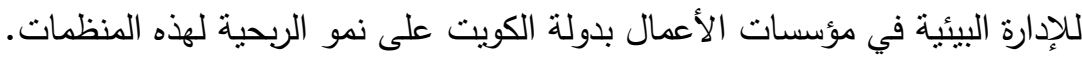

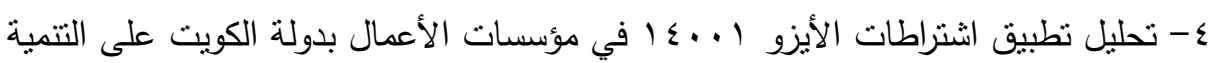
الاقتصادية، وعلي تخفيض تكلفة الإنتاج.

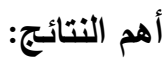
- إن استخدامات مفهوم الأيزو ال...ـا في منظمات الأعمال الكوينية يسهم في وضع البرامج التدريبية الناجحة وفي الحد من معوقات العمل وتدريب الأفراد وتطوير أساليب العمل وتحديد الاختصاصات وإيجاد نوازن بين رغبة الموظف وقراره الثخصي مما نتكل

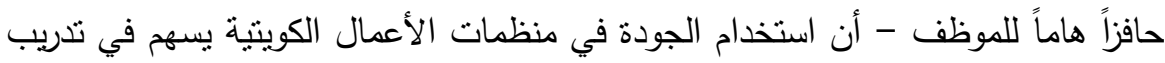
العاملين، وتقديم خدمات متميزة للعملاء، وإنجاز المعاملات التي تخص العملاء، والعمل

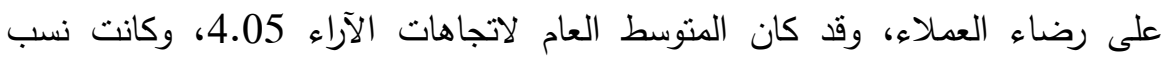

$$
\text { التشتت التي أبرزها الانحراف العام } 0.94
$$

- إن نأثثر استخدام الجودة في الموقف النتافسي للمنشأة له أهمية كبرى في الجودة في الحد

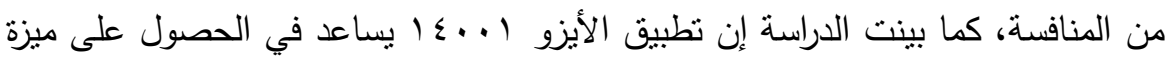
تتافسية، ويسهم في تخفيض التكلفة مما يزيد من أرباح الثركة. 
- إن تأثير الأيزو | ...ـا في استخدام الأساليب الترويجية يساعد في تفعيل دور الإعلان

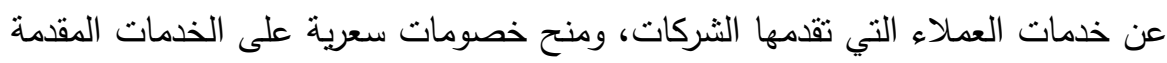
من الثركات مما يزيد من إقبال العملاء، ونتويع الخدمات وترويجها بشكل منظم.

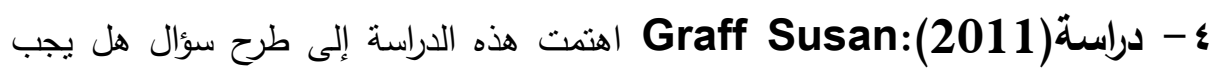
على لشركتكم تطبيق نظام الإدارة البيئة، كما أثنارت إلى ضرورة التطبيق لإدارة البيئة

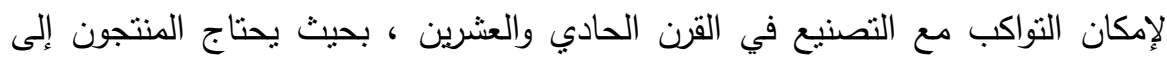

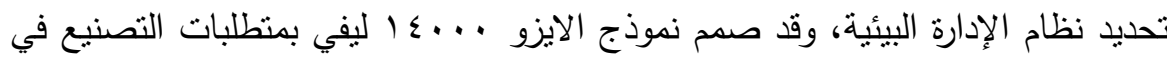

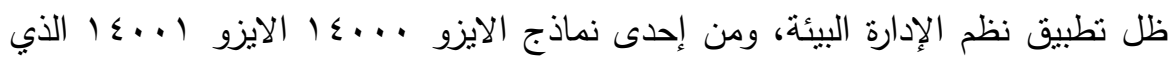

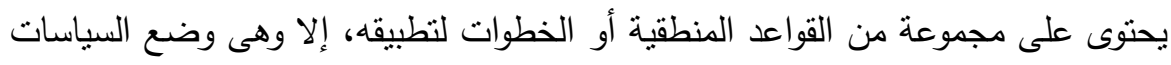

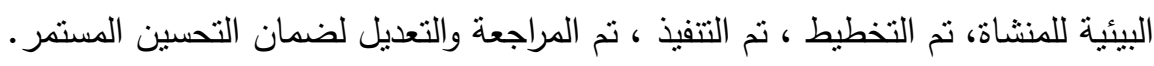

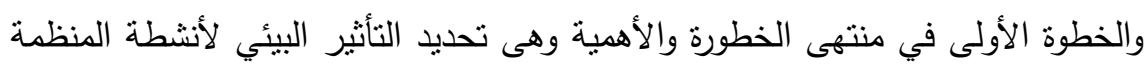
سواء لأنشطة الإنتاجية أو الخدمية تم يليها التخطيط والتطبيق من خلال إصدار وثائق للموارد

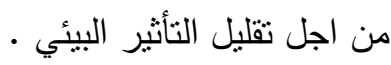

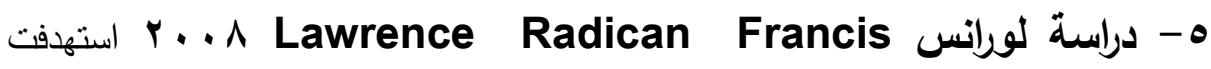
الدراسة معرفة نأثثر المواد الكيماوية التى يتعرض لها العمال سواء من حيث الإصابة

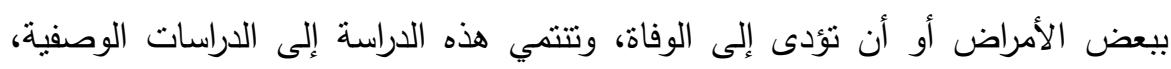
واعنمدت على منهج دراسة الحالة.

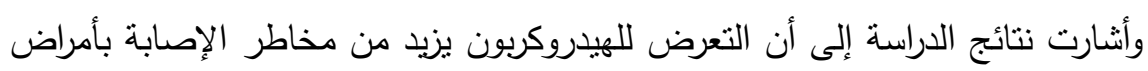
الكلى المزمنة وزيادة نسبة الوفيات. 


\section{الإيجواءايت المنهجية اللصراسة}

1 - متغيرات الدراسة: تعتمد الدراسة على متغيرين أساسيين هما:

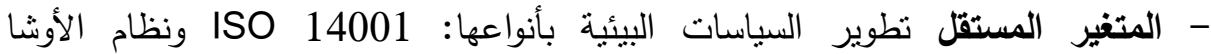
OHSAS 18001 - المتغير التابع الهخاطر التي تتعرض لها المؤسسات الصناعية وهى: الهخاطر التي

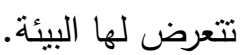
المخاطر التي ينعرض لها العاملين بالمؤسسات الصناعية. r - منهجية الدراسة اعتمد هذه الدراسة على الجوانب الآتية: الجانب النظري: سيتم استيفاء هذا الجانب عن طريق نوعين من الهناهج هها: المنهج الاستقرائي: يتم نكوين الإطار النظري من خلال تجميع المادة العلمية المعلقة

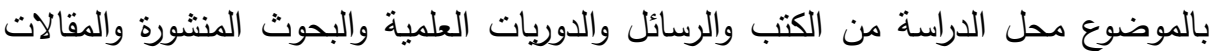
من خلال المسح المكتبي وعبر شبكة المعلومات الالكترونية المحلية والدولية.

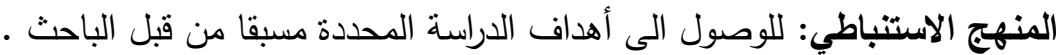

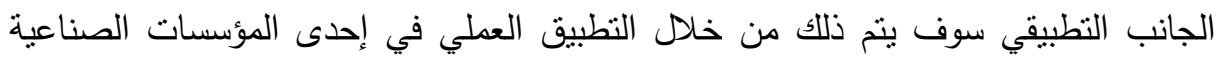
للأساليب المقترحة ومحاولة النوصل الى أهداف الدراسة.

\section{أسالا التراسها}

- استبيان للنحقق من فروض وأهداف الدراسة من خلال عدة محاور يحاول الباحث خلالها

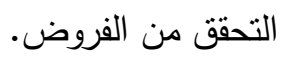

- تناول الاستيان مجموعة من الأسئلة حول البيانات الأولية والتي تثمل: ( النوع - المؤهل

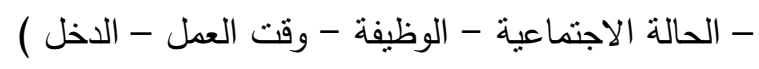

- تتاول الاستيان عدة محاور حول استجابات المبحوثين وتثمل: ( مستوي الوعي بالسياسات

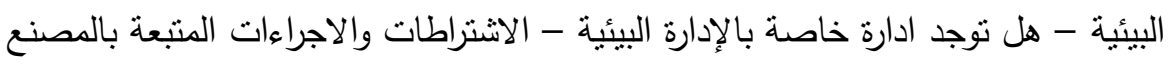
- دورات التدريب والتوعية الخاصة بالسلامة المهنية في الدصنع - علاقة تطبيق الإني 
السياسات البيئية بتخفيض المخاطر الصناعية - المنافع التي تعود علي المنشأة من تطبيق السياسات البيئية - ما هو مناسب لإلزام المنشآت والمصانع بتطبيق معايير الساسة

\section{xaly all}

من أجل الوصول إلى بيانات ذات معنى، تحدد مجال الدراسة في الإداريين من مدراء

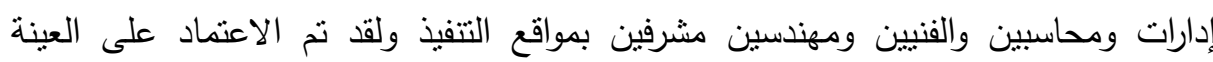

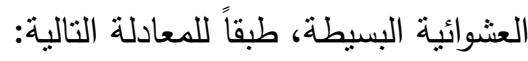

$$
\mathrm{n}_{0}=Z_{\alpha / 2}^{2} P Q / d^{2}
$$

$$
\text { حيث أن }
$$

n

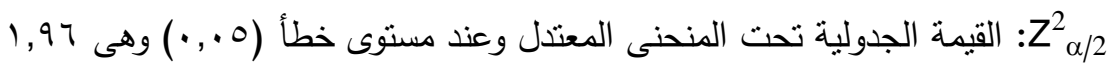
P

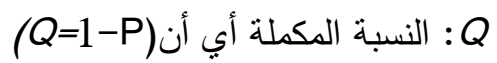

d d درجة الخطأ المسموح بها في عينة الدراسة وقد نم افتراضها من قبل الباحث (0. . . ) ولقد تم احتساب نسبة عدد المفردات التي تتوافر فيها خصائص العينة محل الدراسة هي

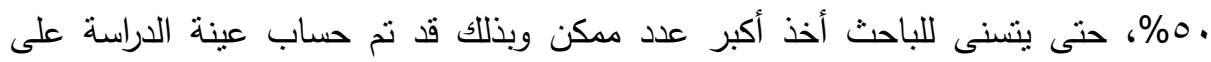

$$
\mathrm{n}_{0}=(1.96)^{2} \times 0.50 \times 0.50 /(0.05)^{2}=384
$$

$$
\text { النحو النالي: - n }
$$

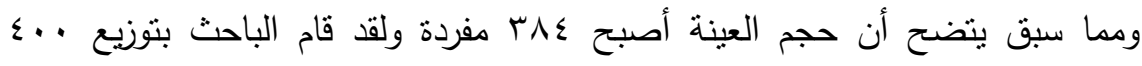

استمارة حتى يضمن استرجاع أقصى عدد من الاستمارات الصالحة، ولقد أعيد منها ل. استمارة صالحة 
صدق قائمة الاستبيان تعرف صلاحية أداة القياس على أنها قدرة الأداة على قياس ما صمدت من أجله ولاختبار صدق استمارة الاستبيان بأقسامها تم استخدام التحليل العاملي، ولقدان قام الباحث بإجراء التحليل العاملي الاستكثافي على جميع المقاييس الفرعية للاستمارة بطريقة

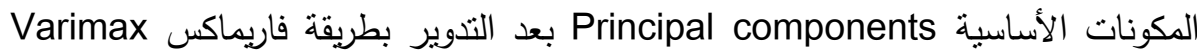
للتوصل إلى عدد من العوامل التي تعبر عن المتغيرات المختلفة للدراسة، وذلك بهدف التأكد من مطابقة تحميل العبارات على ذات العوامل السابق افترضها الباحث من قبل .

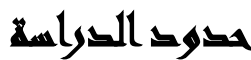

الحدود البشرية: عينة تمنل . 1 مفردة من العاملين بمصنع أحادي سوبر فوسفات بمجمع

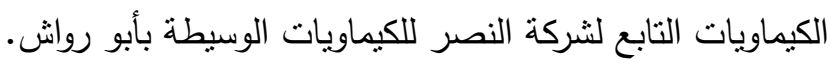

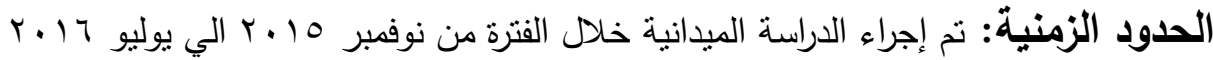
جدول(1): أسباب قياس أثز تطبيق السياسات البيئية علي تخفيض المخاطر في المنشآت الصناعية

\begin{tabular}{|c|c|c|c|}
\hline 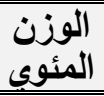 & المعياري & المتوسط & العبارة \\
\hline $97, r$ & •, Or & $\varepsilon, \wedge)$ & 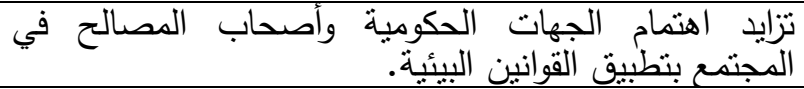 \\
\hline 94,7 & . 70 & $\varepsilon, 7 \wedge$ & 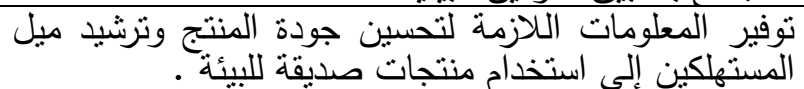 \\
\hline $94, \cdot$ & $\cdot,(>)$ & $\varepsilon, 70$ & لالإدارة والجهات عن الخارجية البيئي من خلال تقارير بيئية تقدم \\
\hline $9 Y, \Lambda$ & . & $\varepsilon, 7 \leqslant$ & 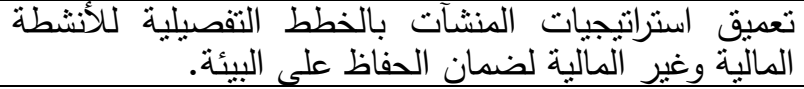 \\
\hline$\wedge r, r$ & $\cdot$, & $\varepsilon$, & المنطلبات البيئية للمنشآت مسئولة فيلاً. الدولة سوف تزيد من \\
\hline$\Lambda \cdot, 7$ & Or & 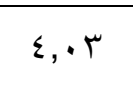 & التكاليف حلبئة المنافسة بين المنشآت وزيادة الإنفاق على \\
\hline $7 V, 7$ & $\cdot, V Y$ & 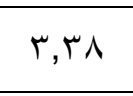 & فيى ألمحافظة المستثرين وأصيئة البئة المنشآت في المشاركة بفعالية \\
\hline$T \varepsilon, \varepsilon$ & $\cdot, 79$ & 1 & 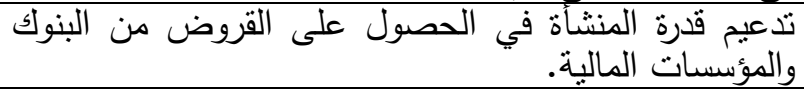 \\
\hline
\end{tabular}

المجلد السادس والثلاثون، الجزء الثالث، ديسمبر 7 ا بـ 
يتضح من بيانات الجدول السابق أن أغلبية عينة الدراسة بنسبة موافقة تراوحت بين

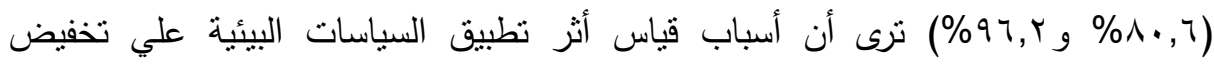

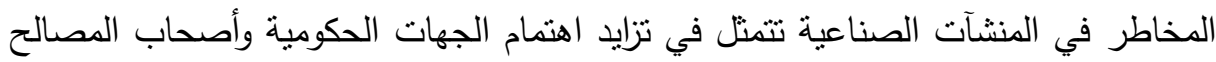
في المجمع بتطبيق القوانين البيئية. وتوفير المعلومات اللازمة لتحسين جودة المنتج وترشيد ميل المستهلكين إلى استخدام منتجات صديقة للبيئة. والإفصاح عن الأداء البيئي من خلال تقارير بيئية تقدم للإدارة والجهات الخارجية. وتعميق استراتيجيات المنشآت بالخطط التفصيلية للأنشطة المالية وغير المالية لضمان الحفاظ على البيئة. وما تفرضه الجهات المسئولة في الدولة سوف تزيد من المتطلبات البيئية للمنشآت مستقبلا. وازدياد حدة المنافسة بين المنشآت وزيادة الإنفاق على التكاليف البيئية، في حين يرى البعض بنسبة موافقة تراوحت بين

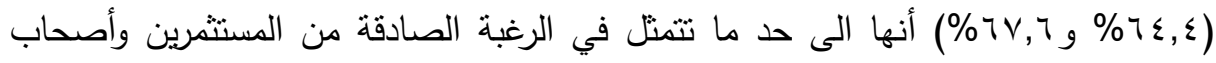

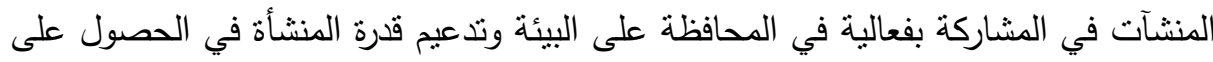
القروض من البنوك والمؤسسات المالية. جدول(ץ): يوضح المنافع التي تعود على المنشآت نتيجة تطبيق السياسات البيئية

\begin{tabular}{|c|c|c|c|}
\hline 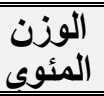 & المعياري & المتوسط & العبارة \\
\hline $97, r$ & r, OT & $\varepsilon, \wedge)$ & 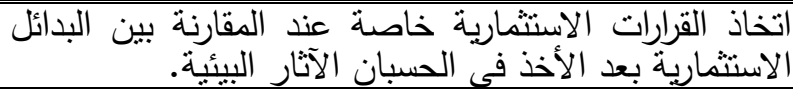 \\
\hline 90,7 &., 0 & $\xi, \vee \wedge$ & توفير وسائل وامكانيات لقياس الآثار الخارجية السلبية للتلوث \\
\hline $9 \varepsilon, 7$ & $\cdot, 0 \leqslant$ & $2, \mathrm{r}$ & احتساب عائدات والتنكاليف البيائية للمنشآت . \\
\hline$\Lambda r, r$ & $\cdot, \varepsilon Y$ & $\{, 17$ & 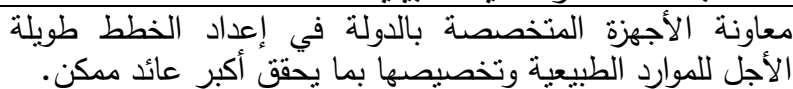 \\
\hline$\wedge r, \cdot$ & $\cdot, \Sigma)$ & $\varepsilon, 10$ & البيئية في الأعتبار بأخذ كافة عناصر التكلفة البيئية وغير \\
\hline$\Lambda Y, T$ & $\cdot, \mu q$ & $\varepsilon, 1 T$ & 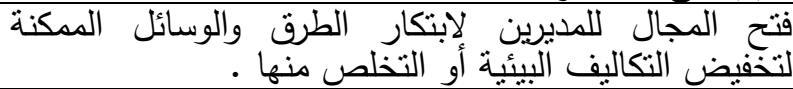 \\
\hline$\Lambda Y, \varepsilon$ & $\cdot, \leqslant 9$ & ir & تأثير التكاليف البيئية بالإيجاب على سمعة وربحية المنشأة . \\
\hline$\Lambda_{r}, \cdot$ & דז, • & $\varepsilon, 1$. & لتحقيق الإدارة البيئية المنلىئيص تلفص الاعتمادات المالية اللازمة \\
\hline$\wedge), \wedge$ & $\cdot, 01$ & $\varepsilon, \cdot 9$ & التقارير السنوية المصروفات والتكاليف والالنزامات البيئية في \\
\hline$\vee 9, \wedge$ & $\cdot, 7 \varepsilon$ & $r, 99$ & تحديد تكلفة المنتجات بطريقة صحيحة \\
\hline
\end{tabular}


يتضح من بيانات الجدول السابق أن أغلبية عينة الدراسة بنسبة موافقة نراوحت بين (ن ثرى أن المنافع التي تعود على المنشآت نتيجة نطبيق السياسات البيئية تتمثل في اتخاذ القرارات الاستثمارية خاصة عند المقارنة بين البدائل الاستثمارية بعد الأخذ في الحسبان الآثار البيئية. و توفير وسائل وإمكانيات لقياس الآثار الخارجية السلبية للتلوث و

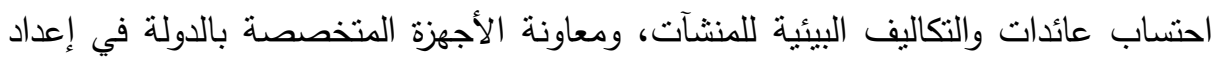
الخطط طويلة الأجل للموارد الطبيعية وتخصيصها بما بحقق أكبر عائد ممكن، وتسعير المنتجات بأخذ كافة عناصر التكلفة البيئية وغير البيئية في الاعتبار وفتح المجال للمديرين لابتكار الطرق والوسائل المكنة لتخفيض التكاليف البيئية أو التخلص منها، وتأنئ وعنير التكاليف

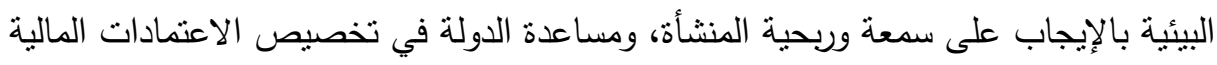

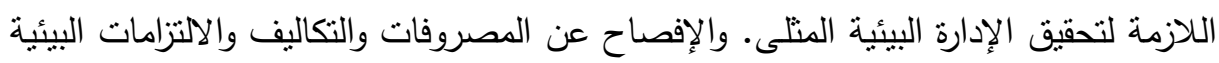

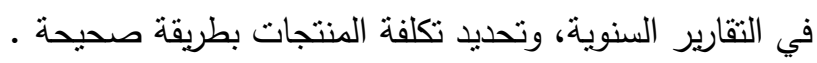
جدول(ץ): يوضح ما هو مناسب لإلزام للمنشآت الصناعية بتطبيق السياسات البيئية

\begin{tabular}{|c|c|c|c|}
\hline 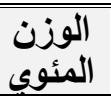 & المعياري & المتوسط & العبارة \\
\hline $9 \pi, \varepsilon$ & $\cdot, 09$ & $\varepsilon, T V$ & 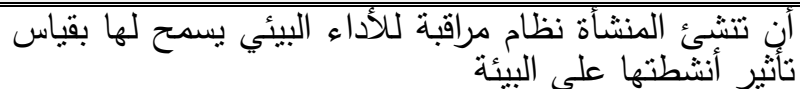 \\
\hline 91,1 & - TV & $\{, 09$ & خارج القوائم المالية عن المعلومات البيئية سواء كانت داخل أو \\
\hline$\Delta r_{,} \cdot$ & $\cdot, \leqslant 1$ & $\varepsilon, 1$ & آنشاطهاً. تطبق المنشآة السياسات البيئية بصرف النظر عن طبيعة \\
\hline$\wedge), \wedge$ & $\cdot$, . & $\varepsilon, .9$ & ورأسمالهيا المنشأة السياسات البيئية بصرف النظر عن حجمها \\
\hline$\Lambda, r$ & $\cdot, 01$ & $\varepsilon, \cdot 7$ & آلقان نطبق المنشأة السياسات البيئية بصرف النظر عن شكلها \\
\hline
\end{tabular}

يتضح من بيانات الجدول السابق أن أغلبية عينة الدراسة بنسبة موافقة نراوحت بين ( نرى أن الإلزام المناسب للمنشآت الصناعية بنطبيق السياسات البيئية

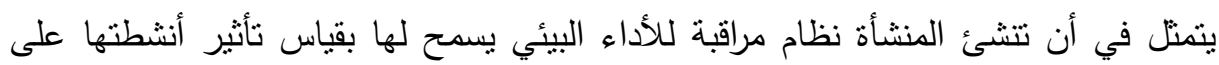

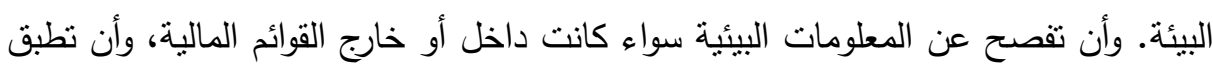

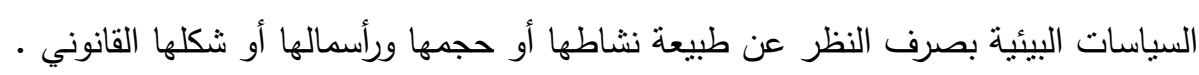


جدول(؛): يوضح العلاقة بين دورات تدريب السلامة والصحة المهنية وخفض المخاطر في

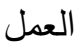

\begin{tabular}{|c|c|c|c|}
\hline المئوين & المعياري & المتوسط & العبارة \\
\hline 90,1 & $\cdot, \S 1$ & $\varepsilon, \vee 9$ & يوجد دورات تدريبية للعاملين. \\
\hline$\Lambda 1, \cdot$ & $\cdot, \leqslant\rceil$ & $\varepsilon, \cdot 0$ & الدورات مفيدة لعملى. \\
\hline$V \Lambda, Y$ & $\cdot, \mathrm{OV}$ & $r, 91$ & أواظب على حضور الدورة المناسبة لي \\
\hline$\checkmark V, \Lambda$ & . TY & $r, \wedge 9$ & الدورة تعرفنى على مسئولياتى بالعمل. \\
\hline $77, \wedge$ & $\cdot, 71$ & $r, \mu \varepsilon$ & الاستماع لَى أثتاء الدورة في آخذ بعض المقترحات. \\
\hline $77, \cdot$ & $\cdot, \mathrm{V} \cdot$ & $r, \mu \cdot$ & التدريب على المعدات والآدوات آثثاء الدورة. \\
\hline Or, ¿ & $\cdot, 9 \leqslant$ & $Y, T V$ & الدورات تتماشيى مع سوق العمل الحالى. \\
\hline$\sum 9,7$ & $\cdot, 9 \leq$ & $Y, \Sigma \wedge$ & معظع الأفراد يلجَاً للذورة للترفيه فقط دون الاستفادة منها. \\
\hline$\sum \wedge, 7$ & $\cdot, \wedge 9$ & $r, \varepsilon r$ & ظروفى لا تساعدنى على حضور الدورات التدريبية. \\
\hline
\end{tabular}

يتضح من بيانات الجدول السابق أن أغلبية عينة الدراسة بنسبة موافقة نراوحت بين

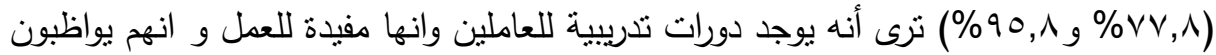
على حضورها حيث تعرفهم مسئوليتهم بالعمل، وكما يرى البعض أنه أحيانا يستمع لي أثناء الدورة في أخذ بعض المقترحات وأحيانا ينم التدريب على المعدات والأدوات أثثاء الدورة وأحيانا

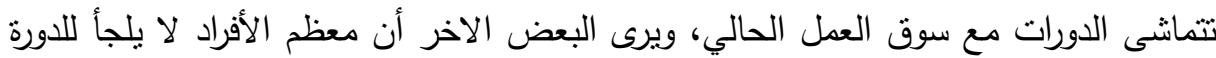
للترفيه فقط دون الاستفادة منها وان الظروف نساعد على حضور الدورات التدريبية.

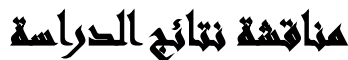

- أن مستوى الوعي بالسياسات البيئية بالمصنع عالي مقابل 10\% للمستوى المتوسط ونسبة

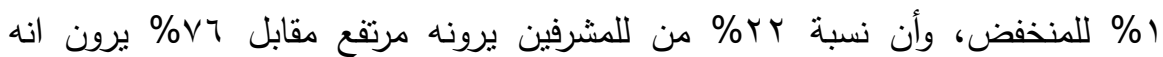
متوسط ونسبة ب\% للمنخفض، ونسبة 9\% من العمالة المساعدة ترى انه عالي مقابل نسبة r^\% ترى انه متوسط ونسبة 9\% للمنخفض، اما العاملين بوحدة السلامة المهنية

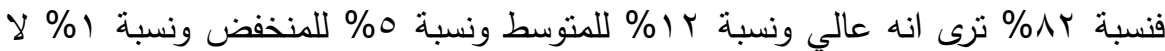
يوجد، - أن الأنشطة المتعلقة بأعمال السياسة البيئية بالدصنع تتبع إدارة الثئون الادارية بالمصنع. 
- صرامة الاشتراطات والإجراءات المتبعة بالمصنع فيما يتعلق بصحة وسلامة الغذاء للعاملين، وكذللك فيما يتعلق بأعمال النظافة ومكافحة الحشرات.

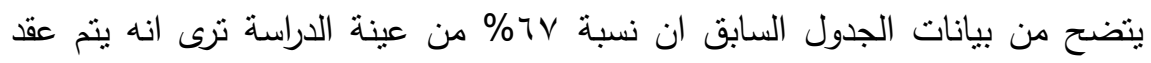
دورات تدريبية بشكل دوري ونسبة rr\% انه عقد دورات تدريبية على فنرات متباعدة ونسبة

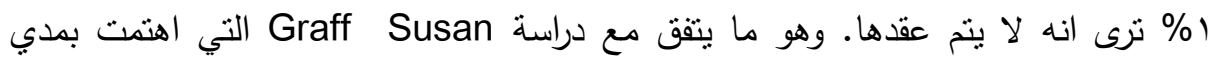

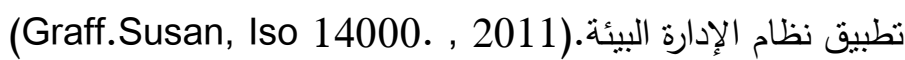
- أن أسباب قياس أثز تطبيق السياسات البيئية علي تخفيض المخاطر في المنشآت الصناعية تتمثل في تزايد اهتمام الجهات الحكومية وأصحاب المصالح في المجتمع بتطبيق القوانين البيئية. وتوفير المعلومات اللازمة لتحسين جودة المنتج وترشيد ميل المستهلكين إلى استخدام منتجات صديقة للبيئة، والإفصاح عن الأداء البيئي من خلاد

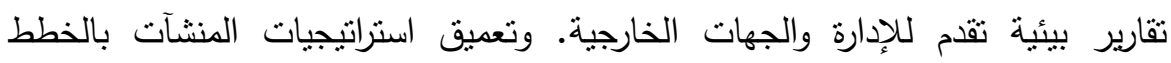

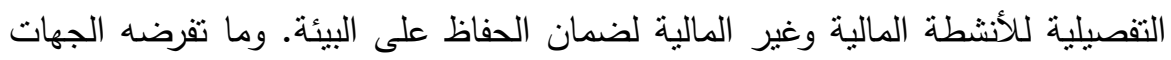
المسئولة في الدولة سوف تزيد من المتطلبات البيئية للمنشآت مستقبلا. وازدياد حدة ولئه المنافسة بين المنشآت وزيادة الإنفاق على التكاليف البيئية، في حين برى البعض بندئ بنسبة

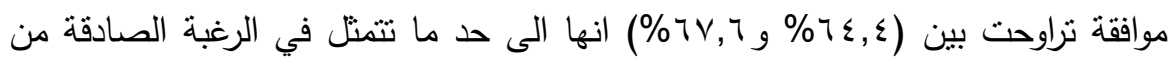
المستثرين وأصحاب المنشآت في المشاركة بفعالية في المحافظة على البيئة وتدعيم قدرة المنشأة في الحصول على القروض من البنوك والمؤسسات المالية، ويتفق ذلك مع دراسة طارق المهدي الأرنؤوط التي اهتمت بدراسة مخاطر بيئة العمل الفيزيائية والكيماوية والهندسية والبيولوجية والنفسية والسلبية وأيضا دراسة التتريعات الوطنية الحاكمة لنشاطات الناته

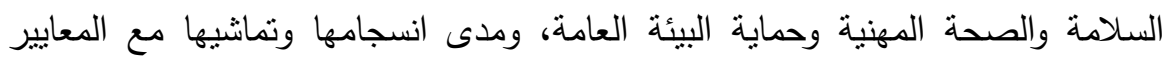

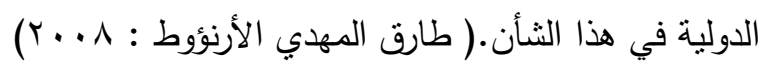
- أن المنافع التي تعود على المنشآت نتيجة تطبيق السياسات البيئية تتمثل في اتخاذ القرارات الاستثمارية خاصة عند المقارنة بين البدائل الاستثمارية بعد الأخذ في الحسبان الآثار البيئية. وتوفير وسائل وإمكانيات لقياس الآثار الخارجية السلبية للتلوث و احتساب عائدات والتكاليف البيئية للمنشآت. ومعاونة الأجهزة المتخصصة وبالدولة ولاتيلة في إعداد الخطط طويلة 
الأجل للموارد الطبيعية وتخصيصها بما يحقق أكبر عائد ممكن. وتسعير المنتجات بأخذ كافة عناصر التكلفة البيئية وغير البيئية في الاعنبار وفتح المجال للمديرين لابتكار الطرق بهن والوسائل الممكنة لتخفيض التكاليف البيئية أو التخلص منها، و تأثثر التكاليف البيئية بالإيجاب على سمعة وربحية المنشأة ـ ومساعدة الدولة في تخصيص الاعتمادات المالية اللازمة لتحقيق الإدارة البيئية المثلى. والإفصاح عن المصروفات والتكاليف والالتزامات البيئية في التقارير السنوية، وتحديد تكلفة المنتجات بطريقة صحيحة، وهو ما يتوافق مع الإدية دراسة:- منال عمارة التي توصلت الي وجود علاقة دالة احصائياً بين السلوك الإيجابي وهي ملئي

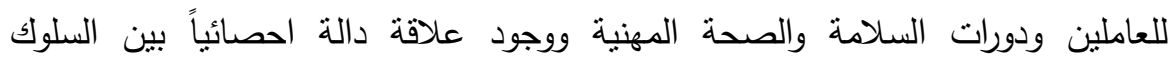

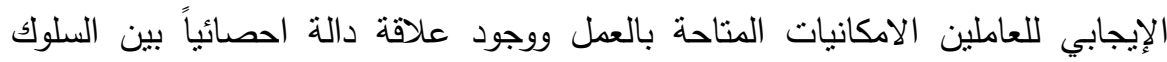

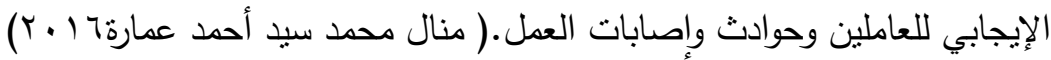

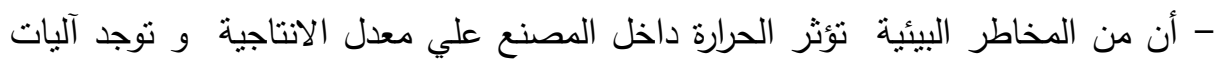

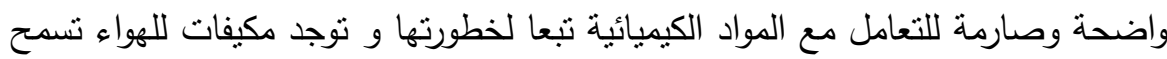
بدرجة حرارة منوازنة مع معدلات العمل وعدم وجود نظام انذار للأخطار والطوارئ مثل ودأل الحرائق ومستويات الاضاءة الموجودة بالمصنع تتاسب ظروف العمل كما ترى الاغلبية انه وله

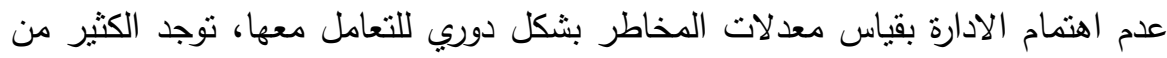

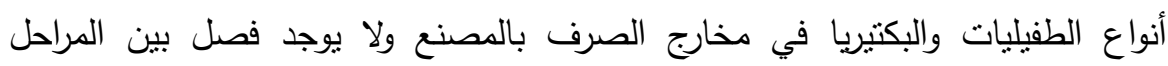
الصناعية يراعي خطورة وحدات الانتاج وتوجد عوازل للصوت لتقليل خطر ضوضاء ولهاء المعدات الصناعية ولا نوجد منظومة محددة لنقل وتداول المواد الخام والتي منها الخطير

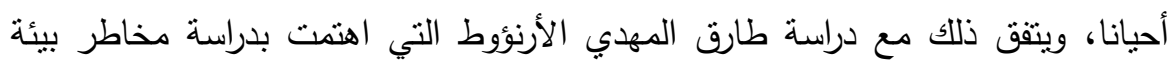

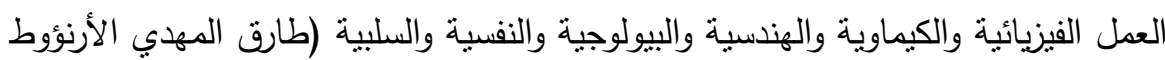

- أن الصعوبات التي تواجه المنشآت في قياس وتحليل تكاليف السياسات البيئية تتمنل في تطبيق السياسات البيئية عملية معقدة وعالية التكلفة و ضعف الوعي البيئي لاى العاملين بالمنثأة للتأثنرات السلبية الاقتصادية والاجتماعية عند إغفال السياسات البيئية. وعدم 
وجود تشريع قانوني يلزم المنشآت بالإعلان عن سياستها البيئية. وعدم اشتراط الالتزام

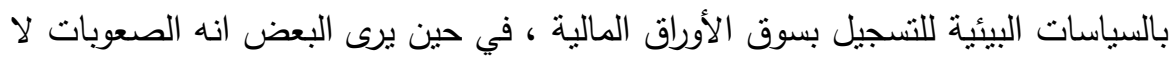
تتمثل في تطبيق السياسات البيئية تتطلب تطبيق أساليب وطرق غير تقليدية وصعوبة

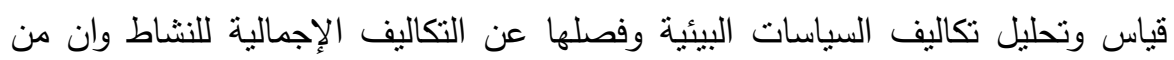
الصعوبات وجود عقبات أو جزاءات واضحة لمن يخالف التشريعات المتعلقة بالبيئة وانه

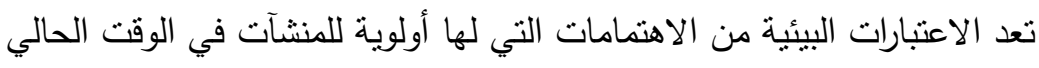

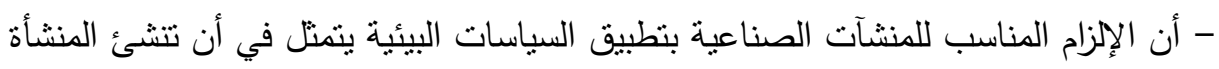

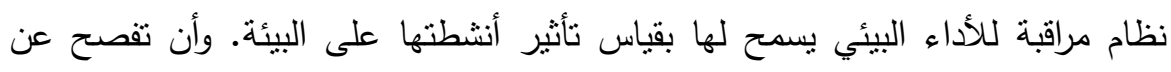
المعلومات البيئية سواء كانت داخل أو خارج القوائم المالية، وأن نطبق السياسات لنيات البيائية بصرف النظر عن طبيعة نشاطها أو حجمها ورأسمالها أو شكلها القانوني .

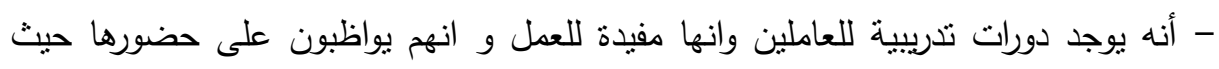

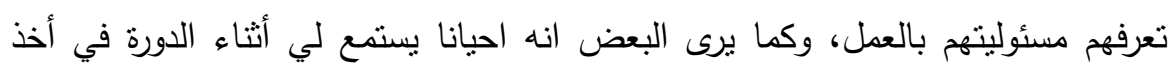

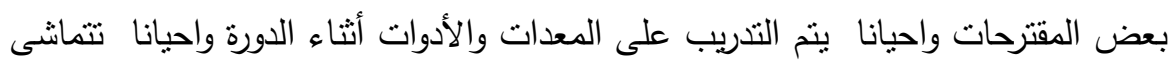
الدورات مع سوق العمل الحالي، ويرى البعض الاخر أن معظم الأفراد لا يلجأ للدورة للترفيه فقط دون الاستفادة منها وان الظروف نساعد على على حضور الدورات التدريبية - أن الامكانيات المتاحة للعمل تتمنل في يتم إيقاف الآلات ويفصل عنها التهات التبار الكهربائي عند صيانتها. ويوجد مساحة كافية حول الماكينات والآلات تسمح بمرور العاملين ولا تعيق أدائهم. والآلات المستخدمة مقاومة للحرائق و يوجد لوحات إرشادية بجوار الآلات. ويوجد

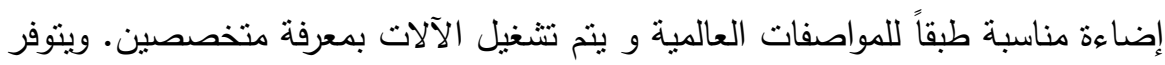

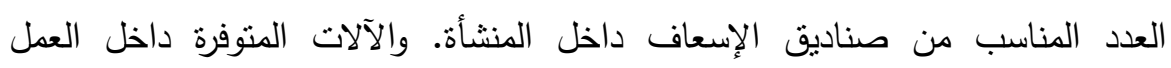

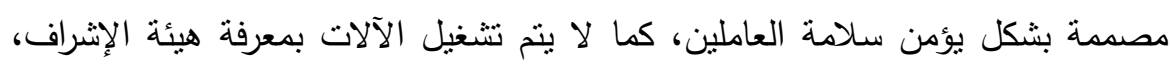

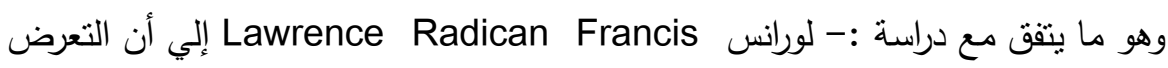
للهيدروكربون يزيد من مخاطر الإصابة بأمراض الكلى المزمنة وزيادة نسبة الوفيات

(Lawrence Radican Francis: 2008) 
- أن المعوقات التي تزيد من مخاطر العمل تتمثل في نقص الكوادر البشرية المدربة ونقص

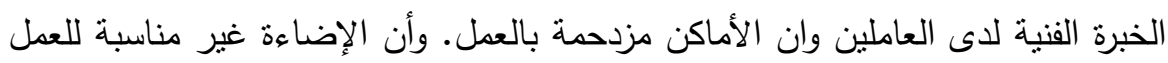
وانه لا ينم تشغيل الآلات بمعرفة متخصصين كما يوجد تضارب في القرارات، وانه ينم إيقاف الآلات ويفصل عنها التيار الكهربائي عند بشكل مفاجئ وانه توجد مساحة كافية

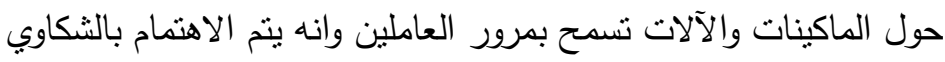
- أن أهم المقترحات التي تحد من مخاطر العمل تتمثل في العمل على التخطيط الجيد وزيادة تدريب الموارد البشرية و العمل على صياغة قوانين جديدة تتمانثي مع العصر الحالي و الأخذ بالوسائل التكنولوجيا الحديثة. و الاهنمام بالثكاوي و زيادة الموارد المالية، ويتنق

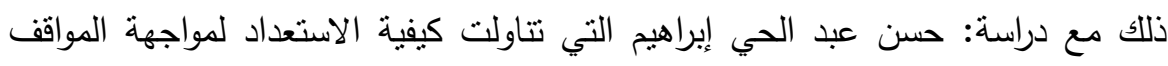

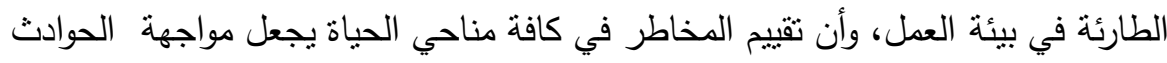

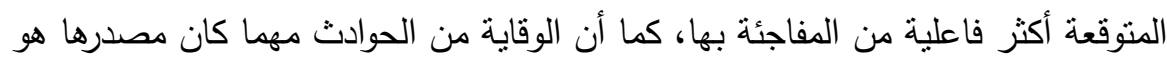

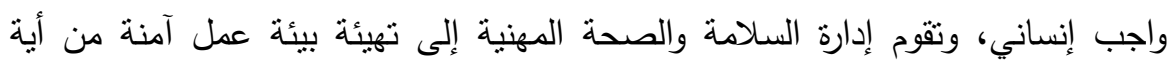
مخاطر أو حوادث مفاجئة للمحافظة على صحة وسلامة العاملين والسكان حول المنشأة

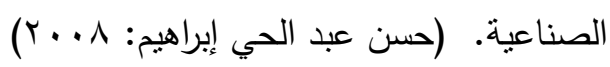

- عدم وجود فرق دال احصائياً بين آراء عينة الدراسة طبقا للمؤهل في الصعوبات التي تواجه

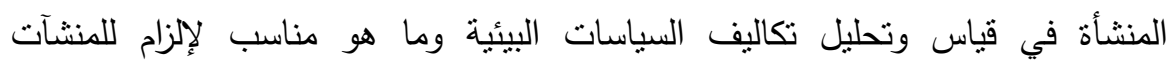
الصناعية بتطبيق السياسات البيئية والمعوقات التي تزيد من مخاطر العمل وأهم

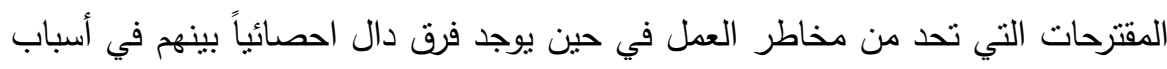
قياس أثر تطبيق السياسات البيئية علي تخفيض المخاطر في المنشآت الصناعية والمنافع التي تعود على المنشآت نتيجة تطبيق السياسات البيئية والعلاقة بين دورات ندريب السلامة والصحة المهنية وخفض المخاطر في العمل والإمكانيات المتاحة بالعمل. - عدم وجود فرق دال احصائياً بين اراء عينة الدراسة طبقا للوظيفة في المنافع التي تعود التئن

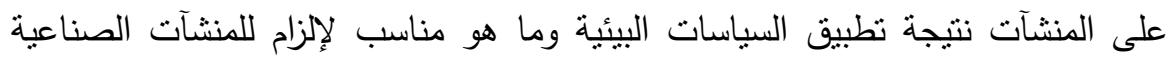

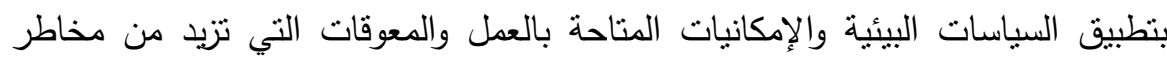


العمل وأهم المقترحات التي تحد من مخاطر العمل في حين يوجد فرق دال احصائياً بينهم في أسباب قياس أثز تطبيق السياسات البيئية علي تخفيض المخاطر في المنشآت الصناعية والعلاقة بين دورات تدريب السلامة والصحة المهنية وخفض المخاطر في العمل وفي الصعوبات التي تواجه المنشأة في قياس وتحليل تكاليف السياسات البيئية - عدم وجود فرق دال احصائياً بين اراء عينة الدراسة طبقا لخيرة العمل في أسباب قياس أثن فئرئ تطبيق السياسات البيئية علي تخفيض المخاطر في المنشآت الصناعية والمنافع التي تعود على المنشآت نتيجة تطبيق السياسات البيئية وما هو مناسب لإلزام للمنشآت الصناعية فئية بتطبيق السياسات البيئية في حين يوجد فرق دال احصائياً بينهم في الصعوبات التي نواجه

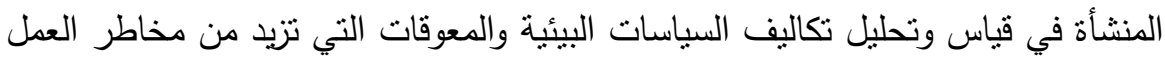
وأهم المقترحات التي تحد من مخاطر العمل والعلاقة بين دورات تدريب السلامة والصحة وندان

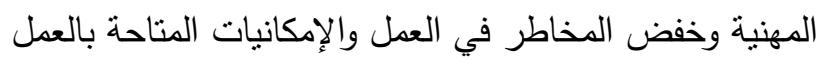

\section{اختبار صحة فروض الاراسة:}

- وجود علاقة معنوية بين نطبيق السياسات البيئية وتخفيض المخاطر في المؤسسات الصناعية. مما بدل على صحة الفرض.

- وجود علاقة جوهرية بين تطبيق السياسات البيئية والمخاطر في المؤسسات الصناعية، حيث بلغت قيمة "معامل الارتباط" VAV,, · عند مستوى دلالة ا.,., ، مما بدل على كلما

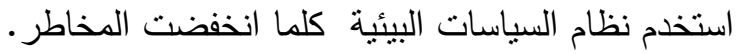

- وجود علاقة جوهرية بين المخاطر في المؤسسات الصناعية والمنافع التي تعود على المؤسسات الصناعية، حيث بلغت قيمة "معامل الارتباط" VYO, . عند مستوى دلالة

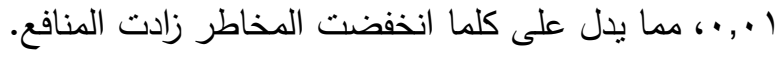
- وجود علاقة معنوية بين بين المنافع التي تعود على المؤسسات الصناعية وتطبيق

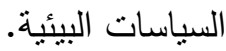
- وجود علاقة معنوية بين التزام المؤسسات الصناعية بنطبيق السياسات البيئية الخاصة بنظام ادارة الصحة والسلامة المهنية وتخفيض المخاطر في المؤسسات الصناعية. 
- وجود علاقة معنوية بين دورات تدريب السلامة والصحة المهنية وتخفيض المخاطر في المؤسسات الصناعية. - وجود علاقة معنوية بين الامكانات المتاحة في المؤسسات الصناعية وخفض المخاطر فيها. - وجود علاقة معنوية بين المعوقات وخفض المخاطر في المؤسسات الصناعية.

\section{تروياهي التوراسلة}

1- ضرورة قبام المؤسسات الرقابية بممارسة أعمالها الرقابية على المنشآت الصناعية بصورة دورية ودون انقطاع، كما يجب أن تلتزم بتحديد فترات كافية وملائمة للقيام بعمليات التفنش على المنشآت الصناعية وذللك للتأكد من نطبيق الانظمة واللوائح والقوانين

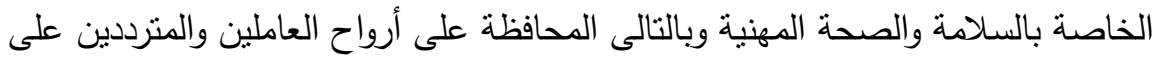
المنشآت الصناعية.

r- لابد من اهتمام المؤسسات الرقابية والمؤسسات الصناعية بالعمل على نطوير الأنظمة

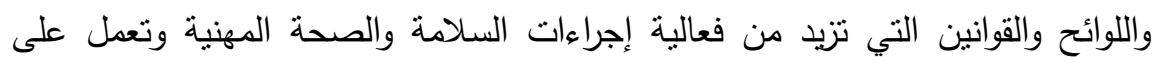

$$
\text { التقليل من الحوادث والإصابات والأمراض المهنية. }
$$

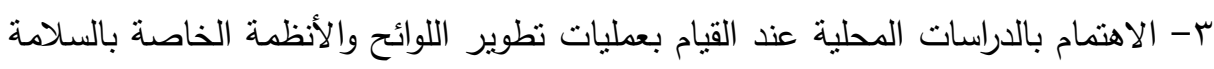

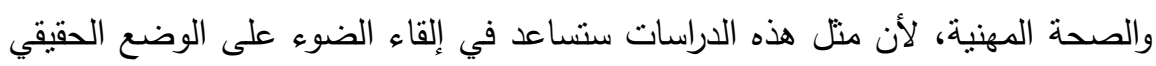

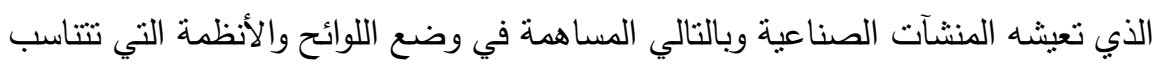

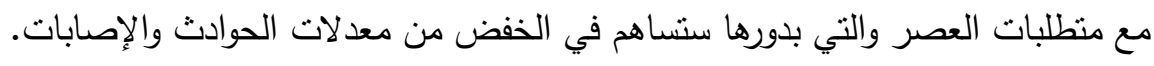

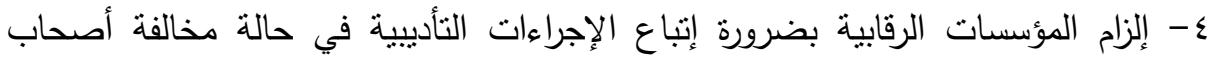

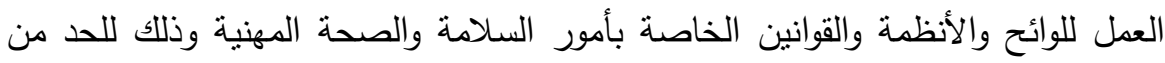
الخسائر البشرية والاقتصادية التي تتعرض لها لها المنشآت الصناعية. 
ه- قيام المؤسسات الرقابية بالرفع من مستوى التأهيل والتدريب لاى أصحاب المؤسسات الصناعية فى مجال السلامة والصحة المهنية وتوعيتهم بأهمية قيام المنشآت الصناعية

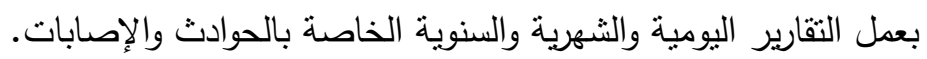

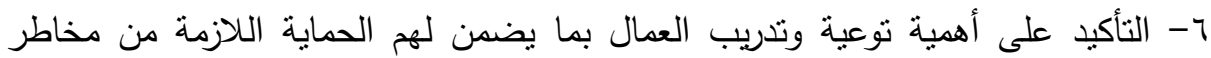
العمل وتتفيذ برامج التدريب المستمر بهدف تطوير خبراتهم العلمية ومهاراتهم التقنية وتتمية

$$
\text { الوعي الصحي لديهم. }
$$

V اهنمام أصحاب العمل بتوفير ظروف عمل آمنة للعاملين داخل المنشآت الصناعية من لوأن حيث العوامل الفيزيائية والكيميائية والحيوية والميكانيكية والعمل على توفير معدات الوقاية الثخصية اللازمة للحد من ارتفاع نسبة الإصابات.

^- التأكيد على التزام الإدارة العليا بالاهتمام بصفة شخصية بأنشطة الأنسات الأمان على أساس روتيني مع إعطاء مسألة الأمان الأولوية في الاجتماعات وإعطاء مسئولي الأمان المكانة

$$
\text { العالية في المنشأة. }
$$

9- ضرورة اهتمام المنشآت الصناعية بوجود مفتش داخلي لمراقبة السلامة والصحة المهنية والتأكد من أن المنشأة تلنزم بتوفير وتطبيق جميع ما يلزم لزيادة فعالية إجراءات السلامة

$$
\text { والصحة المهنية. }
$$

• 1- الاهتمام بموضوع التوعية والتتقيف الجماهيري عن طريق وسائل الإعلام العامة حول أهمية السلامة والصحة المهنية ودورها في الحماية والحفاظ على البيئة العامة.

\section{zall}

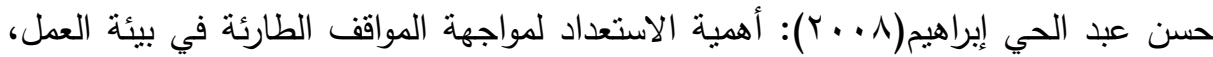
المؤتمر العربي الثاني، معهد الدراسات والبحوث البيئية، جامعة عين شمس.

طارق المهدي الأرنؤوط(^ . . ب): السلامة والصحة المهنية وتأمين بيئة العمل وحماية البيئة

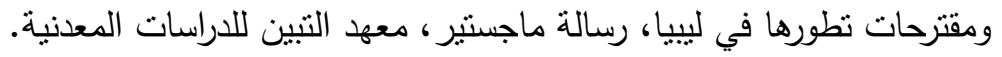

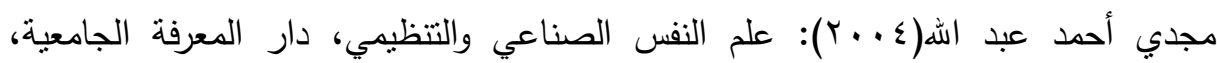

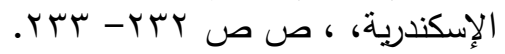

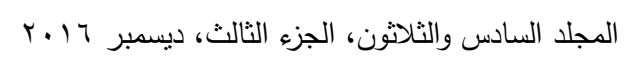




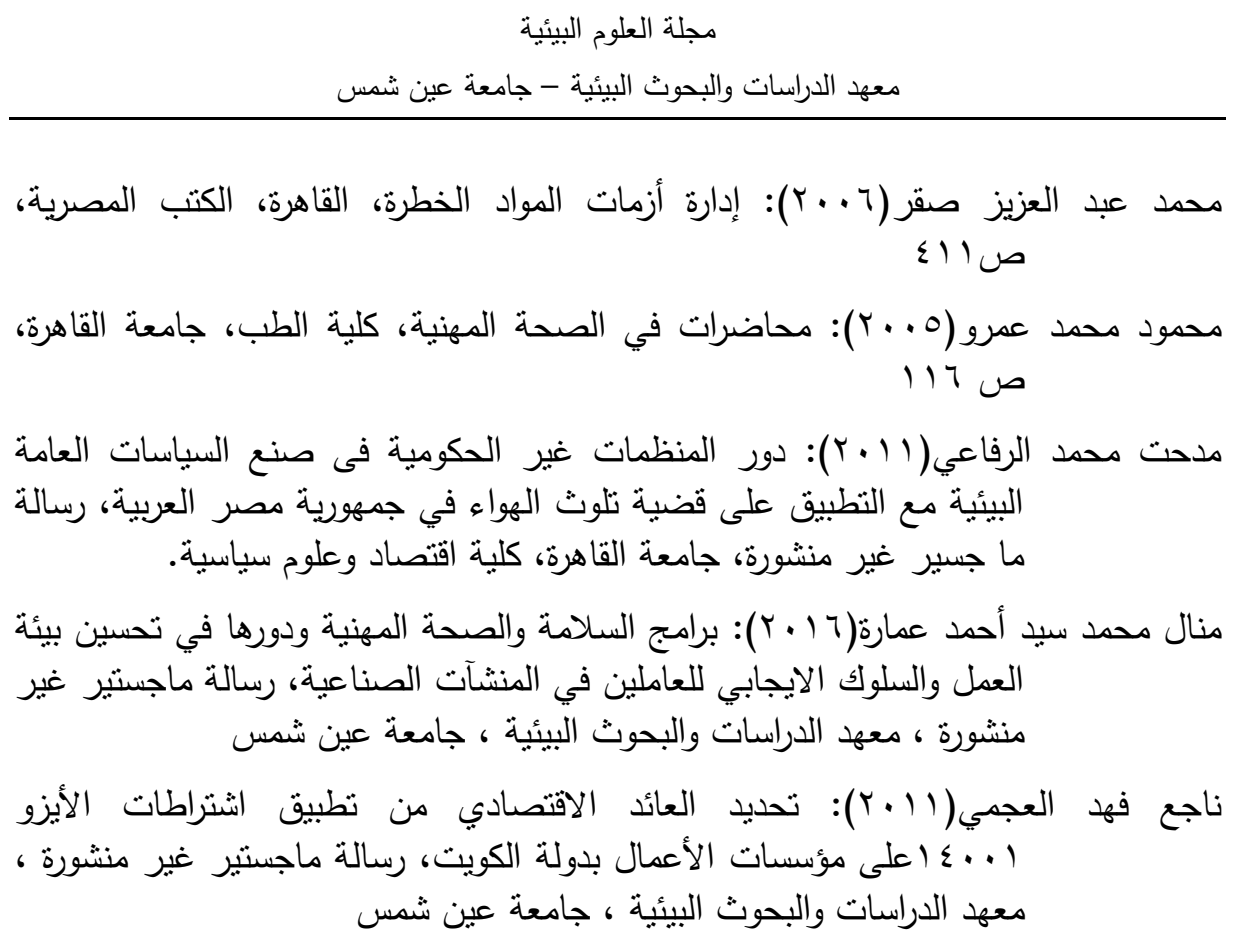

Elizabeth Walsh Nancy( 2004): Abusiness Ethics Approach to Hazard Communication And Employee Right to Know , $\mathrm{PhD}$, University of Minnesota.

Franciso Szckely (2005):. in Collaboration with UNDP Guidilines For Environmental Management and Sustainable Development January,. p. 11 .

Graff.Susan, (2011): Iso 14000.should your Company Develop an Environmental Management System? Industrial Management, ,pp.19.22

Lawrence Radican Francis (2008): A retrospective Cohort Study of Chronic Kidney Disease in Workers Exposed to Trichloroethylene \& Other Slovents, Phd, University of New Jersey,. 
Taylor, Jonr : Pollutiants (2004): Estimating Personal Exposures Based on Mass Balance Material Usage Rates : Validation of A ventilation Model in a Spray Paing Booth , ( N.Y Journal of Occupational Environmental Hygiene, Vol I Issue 4, Ap), P. 213.

\title{
THE IMPACT OF ADOPTING DEVELOPMENT OF ENVIRONMENTAL POLICIES IN REDUCING RISKS IN INDUSTRIAL INSTITUTIONS WITH APPLICATION ON CHEMICAL INDUSTRIES
}

Refaiy, M. A. ${ }^{(1)}$; Abdel Hafez, M. ${ }^{(1)}$ and Khaled, O. K. M. ${ }^{(2)}$ 1) Faculty of Commerce, Ain Shams University 2) EL Nasr for Intermdlate Chemical

\begin{abstract}
The Egyptian institutions, especially the industrial ones adopted for the development of environmental policies and of Standard ISO 14001 concerned with environmental management systems in order to improve and develop the environmental protection systems and OHSAS 18001 ohsas own occupational health and safety management in order to risk to personnel reduction, it will achieve many of the goals of industrial enterprises of including: gain a competitive advantage, entering into new markets, raise the efficiency of workers, improve the quality provided and speed product delivery of the markets, and the study aimed to identify the impact of the adoption of environmental policies in the risks to the environment and working to reduce the development, the study used a systematic induction and deduction through a questionnaire has been applied to 100 single workers factory Super phosphate complex chemical Inc.'s victory for intermediate Chemicals Abu Rawash mono, and the study found: - the presence of a

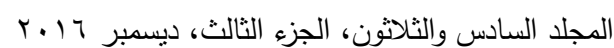


مجلة العلوم البيئية

معهد الدراسات والبحوث البيئية - جامعة عين شمس

substantial relationship between the application of environmental policies and the risks in the industrial enterprises, the more used environmental policy system the lower the risk, the study suggested: issuing regulations depending specialized industrial activities include regulations and standards associated with each industrial activity to ensure specific specialized standards. 